\title{
RELOJES DE BOLSILLO EN LA CORTE ESPAÑOLA: JOYAS PARA MEDIR EL TIEMPO
}

\section{Pocket-watches in the Spanish court: jewels to measure time}

\author{
Amelia ARANDA HUETE \\ Dirección de las Colecciones Reales \\ Patrimonio Nacional \\ amelia.aranda@patrimonionacional.es
}

Fecha de recepción: 10/12/2017

Fecha de aceptación definitiva: 26/02/2018

RESUMEN: La necesidad de controlar el tiempo y regular la rutina diaria obligó a los relojeros a fabricar los primeros relojes de uso personal. Desde el primer momento se convirtieron en un objeto de lujo anhelado por los clientes más adinerados. En el siglo XVIII se asociaron lujo y precisión. Los relojes se convirtieron en un objeto indispensable para la vida cotidiana. Los reyes españoles, al igual que otros monarcas europeos, se convirtieron en grandes poseedores y coleccionistas de estos objetos. Adquirieron ricos ejemplares fabricados en oro y plata, enriquecidos con piedras preciosas, firmados por los mejores relojeros europeos. La mayoría fueron suministrados por comerciantes y por los embajadores de Londres y de París. Las cuentas registradas en la tesorería general son el mejor instrumento para conocer estas adquisiciones.

Palabras clave: reloj; repetición; lujo; relojería francesa; relojería inglesa; monarquía.

ABSTRACT: The necessity of measuring time and of regulating the daily routine forced the clockmakers to manufacture the first personal clocks. Since the very first moment it became a luxury object coveted by the wealthiest customers. In the $18^{\text {th }}$ century luxury and precision became associated. Clocks became an essential object 
for the daily life. The Spanish kings, as well as the rest of the European royalty, became great owners and collectors of these objects. They invested in expensive clocks produced with gold and silver, enriched with gemstones and signed by the best European clockmakers. Most of them were supplied by traders and ambassadors from London and Paris. The accounts registered on the national treasury are the best way to became acquainted with these acquirements.

Key words: montre; watch; French watchmaking; English watchmaking; luxury; repetition; monarchy.

La necesidad de controlar el tiempo en las tareas cotidianas, en los viajes comerciales e incluso en el campo de batalla propició que los artífices relojeros desarrollaran y fabricaran los primeros relojes de uso personal. Para ello fue imprescindible reducir el tamaño y el peso de los distintos componentes del reloj de mesa portátil para facilitar que una persona pudiera llevarlo en el bolsillo o en la faltriquera ${ }^{1}$.

Gracias a los documentos conservados algunos investigadores fechan los primeros relojes de bolsillo a finales del siglo $\mathrm{XV}^{2}$. Se desconoce el lugar donde se elaboró el primer ejemplar porque varios relojeros de distintas nacionalidades construyeron simultáneamente relojes de pequeño tamaño. Desde el primer momento se convirtió en un objeto de lujo anhelado por reyes, príncipes, nobles y personas con fortuna interesados por los objetos mecánicos ${ }^{3}$. En la decoración de las cajas se emplearon las técnicas más ricas y refinadas. Plateros de oro y plata, lapidarios, cinceladores y esmaltadores contribuyeron a la creación y a la decoración de cajas de perfiles variados: esféricos, ovales, circulares, octogonales, estrellados, en forma de cruz, etc. La demanda de esta rica clientela fue satisfecha por los primeros centros relojeros de Augsburgo, Nuremberg, Blois, París y Ginebra.

Estos primeros relojes se lucieron suspendidos de largas cadenas. En un retrato masculino atribuido a Haut-Rhin, fechado en 1567, conservado en el Museo Nacional de Nuremberg observamos como el caballero lleva colgando del cuello, gracias a una rica y gruesa cadena de tres vueltas, un bello ejemplar de oro o latón dorado, cincelado, con anillo horario de plata y una sola aguja ${ }^{4}$.

1. Estos relojes recibieron también el nombre de repeticiones y de muestras.

2. CARDInAL, Catherine. La montre des origines au XIX siècle. Fribourg: Office du Livre, 1985. p. 13. Sin embargo, CHAPIRO, Adolphe. La montre française du XVt siècle jusqu'à 1900. Paris: Les éditions de l'Amateur, 1991. p. 7 afirma que fue a principios del siglo XVI.

3. Uno de los primeros retratos de caballero sosteniendo en la mano un reloj de bolsillo fue pintado por Tommaso Manzuoli hacia 1558. Se conserva en el Museo Nacional de Ciencia e Industria de Londres. Publicado por Thompson, David. The History of watches. New York-London: Abbeville Press Publishers, 2008.

4. CARDINAL, Catherine. "L'horloge, un objet emblématique de la Renaissance». En Tresors d'horlogerie, le temps et sa mesure du Moyen Âge à la Renaissance. Avignon: Éditions RMG, 1998. p. 8. 
A principios del siglo XVII la relojería francesa se afianzó y aumentó su producción gracias al apoyo de la monarquía y al incremento de la clientela. Se consolidó la caja de contorno redondeado, algo abultada todavía, fabricada en latón y en plata. Ambos materiales armonizaron creando cajas de gran belleza decoradas con motivos geométricos, lacerías y escenas figuradas cinceladas y grabadas. El esmalte comenzó a emplearse en el ornato de las cajas prefiriéndose la técnica champlevé a la cloisonné por su fácil ejecución. Primero se aplicó en la esfera y después en la caja combinándose con piedras preciosas engastadas en bocas cerradas. Con frecuencia se alternaron con gran habilidad el esmalte opaco y el traslúcido. Este último permitía apreciar mejor el trabajo elaborado por el cincelador en el metal.

El esmalte pintado triunfó en el segundo cuarto del siglo XVII por su resistencia y por permitir la representación de escenas de gran belleza gracias a la vivacidad de los colores. El esmalte envolvía la totalidad de la caja, tanto la tapa delantera como la trasera e incluso el interior de ambas, constituyendo en muchos casos un completo programa iconográfico. Los motivos decorativos estaban inspirados en la naturaleza, en la botánica, en la historia y en la mitología. La mayor parte de estas cajas esmaltadas se fabricaron en Francia y desde allí se distribuyeron por el resto de Europa.

La relojería inglesa destacó por la calidad técnica de sus mecanismos y fue ganando terreno a la francesa hasta convertirse en el último cuarto del siglo XVII en la preferida por un público mayor. Las condiciones económicas favorables y la estabilidad política beneficiaron la aparición de una próspera burguesía enriquecida gracias al comercio del algodón y de la lana. La invención del resorte en espiral por el físico holandés Christiaan Huygens en 1675 revolucionó la relojería e impulsó la conquista de la precisión en la medición del tiempo ${ }^{5}$. Además, los relojeros hugonotes que huían de Francia a causa de las persecuciones religiosas fueron acogidos por Inglaterra y ayudaron, con sus cualificados conocimientos, al fomento de esta escuela ya que se les permitió desarrollar su arte con total libertad y practicar el comercio. Aunque a partir de ese momento el reloj dejó de ser una joya y se convirtió en un objeto útil y práctico, las cajas continuaron fabricándose en metal dorado y en plata y adornándose con bellos grabados y repujados en ocasiones embellecidos con esmalte y piedras preciosas. El talento de afamados relojeros como Thomas Tompion, Daniel Quare y George Graham potenció la creación de máquinas dotadas de importantes innovaciones técnicas que preconizaron la relojería moderna.

A estos dos centros relojeros se unió la floreciente escuela suiza que comenzó a despuntar en la segunda mitad del siglo XVII, especialmente en la fabricación de cajas esmaltadas. Los orfebres de Ginebra comprendieron que esta actividad les podría reportar ingresos extras.

5. Chapiro. Op. cit., pp. 35-36. 
A partir de 1720 la relojería francesa resurgió. El lujo se asoció al interés manifestado por los relojeros en aplicar sus conocimientos técnicos en las máquinas y obtener mayor rendimiento. Así atrajeron a una clientela interesada por el refinamiento y por la ciencia. Los vestidos, las joyas, los guantes, los sombreros, los bastones y los relojes, como parte de la indumentaria, se convirtieron en accesorios muy elegantes, indispensables para la clase adinerada. La nobleza poseía la mayor parte de la riqueza y la invirtió en comprar estos productos. Pero también fueron adquiridos por los comerciantes, los notarios, los abogados y todas aquellas personas que necesitaban demostrar su alto poder adquisitivo y crear hábitos rutinarios en sus tareas profesionales. De esta manera se fomentó el trabajo de los artífices y se promovió el comercio de estas obras de arte.

Los hombres y las mujeres los usaban a pares. Cardinal ${ }^{6}$ argumenta que este doble uso se debió a la necesidad de tener que comparar la hora en ambos ejemplares y verificar que ésta fuera exacta. Los figurines de moda publicados en Europa en esta época son un buen testigo. Los lucían colgando de la cintura rematando magníficas châtelaines. En un retrato de la reina María Luisa de Parma pintado por Zacarías González Velázquez intuimos dos relojes prendidos de sendas châtelaines caladas (Museo de Historia de Madrid). En tres tapices conservados en el Palacio Real de El Pardo y en el Palacio Real de Madrid diseñados por el pintor José del Castillo apreciamos varios personajes alhajados con uno o dos relojes de bolsillo suspendidos de châtelaines.

La chatelâine comenzó a utilizarse hacia 1730. Estaba integrada por tres o cuatro placas unidas por asas y reasas. De las primeras placas, en forma de escudete, se suspendían la llave, el sello, pequeños perfumadores y otros accesorios. El reloj se enganchaba a la última placa y su caja siempre estaba decorada a juego con el resto de la pieza ${ }^{7}$.

\section{MATERIALES Y TIPOLOGÍA}

A finales del siglo XVII el reloj francés adquirió unas señas de identidad que le diferenciaron de los elaborados en otros centros relojeros. Comenzó a fabricarse el denominado oignon Louis XIV, un tipo de reloj muy característico que jugó un importante papel en la historia de la relojería francesa y que continuó en uso durante todo el siglo XVIII. Presentaba numerosas innovaciones técnicas pues, además de estar dotado de un regulador con volante y espiral, se complementó con mediciones astronómicas, calendarios, fases de la luna, etc. La caja de los primeros oignon se confeccionó en latón dorado y en algunas excepciones en plata. Raros fueron los ejemplares elaborados en oro. El metal se adornó con

6. CARDinal. La montre..., p. 49

7. Cummins, Genevieve. How the watch was worn. A fashion for 500 years. Suffolk: Antique Collectors' Club, 2010, pp. 19-41. 
motivos vegetales y geométricos - cenefas, hojas de acanto, palmas- que convivieron con pájaros, esfinges, mascarones y escenas mitológicas, todo ello repujado y en relieve. Las bellas composiciones se inspiraron en los principales tratados de ornamentistas como Jean Bérain, Simon Gribelin, Pierre Bourdon, Daniel Marot y reflejaron la evolución de los estilos decorativos.

Las esferas, algo abombadas, eran de latón dorado y se cubrieron con esmalte blanco imitando la porcelana. Uno de los modelos presentaba una placa lisa, blanca, con gruesas cifras romanas policromadas en negro o en azul. Otro, una placa de latón, dorada y repujada con motivos de follajes y sobre ella placas rectangulares, independientes -conocidas como cartuchos-, esmaltadas en blanco con grandes cifras horarias policromadas en negro y en azul. El tercer modelo se revestía enteramente con esmalte blanco, pero cada cifra se abombaba y enmarcaba por una línea policromada en negro simulando cartuchos. Todos los ejemplares tenían una sola aguja, elaborada en acero, rematada en una flor de lis o en una flecha. La firma del relojero se solía ubicar en el centro coincidiendo con el eje de la aguja. La toma de cuerda para el remontaje de la máquina casi siempre se situó entre las cifras III y IV.

Un componente esencial para el funcionamiento del reloj era el coq o galluza, pieza de metal que protegía el escape y el volante espiral ocupando casi toda la platina. Se convirtió en un elemento indispensable y desde el principio se decoró con gran elegancia y refinamiento. Siempre dorado, presentaba una superficie circular u ovalada que permitía a los cinceladores realizar un diseño calado reproduciendo líneas sinuosas, ejemplos claros del estilo barroco imperante en la época.

Hacia 1700 comenzó a elaborarse en Francia el reloj de repetición, muy útil para conocer la hora durante la noche. Para su funcionamiento se añadió la aguja de los minutos. Se impuso definitivamente la esfera esmaltada de blanco con las cifras horarias policromadas en negro. Anillos interiores o exteriores marcaban de cinco en cinco los minutos, bien a base de pequeños segmentos o elementos geométricos, bien con números árabes pintados en negro. Las agujas, cinceladas, eran de oro o de latón dorado.

Coincidiendo con estos modelos, algunas cajas se recubrieron con cuero y con zapa y se adornaron con clavos de cabeza redonda, de diámetro variado, realizados en oro o en plata reproduciendo diseños geométricos, vegetales, arabescos y monogramas. Estos relojes de aspecto sobrio y robusto contrastaron con los de años anteriores y posteriores ya que presentaron un aspecto más funcional que decorativo.

Durante el reinado de Luis XV de Francia el reloj volvió a concebirse como un objeto de lujo. Inspirado en el oignon, el tamaño de la maquinaria disminuyó y la caja, ejecutada con gran refinamiento y exquisitez, se decoró con motivos grabados, escenas esmaltadas y piedras preciosas engastadas en bocas cerradas. El estilo rococó dominó y muchas de las cajas fueron diseñadas por célebres grabadores como Juste-Aurèle Meissonnier, quien publicó en 1734 un Livre d'ornemens. 
El fausto y la pompa de la corte francesa potenciaron la fabricación de auténticas joyas elaboradas casi siempre en oro. Los asuntos más solicitados, inspirados en los cuadros de Watteau, Carle van Loo, Boucher, Fragonard, reprodujeron en esmalte pintado escenas pastoriles y galantes, motivos que simbolizaban el amor, retratos de damas jóvenes, instrumentos musicales o simples adornos de flores. La escena principal protagonizaba la tapa trasera y en el interior o contraesmalte figuraba un paisaje. La tapa delantera era de cristal y protegía la esfera de esmalte blanco. Poco a poco se impuso la moda de reducir la escena esmaltada a un medallón central, enmarcado por pedrería y rodeado de zonas de metal cincelado y grabado simulando rocalla, volutas, lazos, conchas y guirnaldas. El borde y la tapa a veces se embellecieron con perlas y diamantes. Incluso se embutieron pequeños diamantes rosas en las agujas, en el arranque de la cadena o en la lengüeta.

Convivieron con otras cajas, solo de metal, grabadas y cinceladas, que copiaron la nervadura asimétrica de una concha o representaron escenas en bajo relieve realizadas en varios tonos de oro para crear riqueza cromática. En casi todas las máquinas de estos relojes se utilizó el escape de rueda de encuentro o escape de varilla $^{8}$. Grandes relojeros aportaron importantes innovaciones técnicas. El más destacado fue Julien Le Roy, quien, además de escribir varios tratados de relojería, fue el primer relojero en numerar sus piezas siguiendo el ejemplo de los maestros ingleses. Su hermano Pierre inventó, al igual que él, nuevos escapes para regular con mayor exactitud la marcha del reloj.

Hacia 1765 la mayoría de los relojes franceses eran de pequeño tamaño porque se redujo la máquina y sobre todo el órgano regulador. Unos años después, en 1770, Jean-Antoine Lépine transformó el concepto de reloj aplicando una serie de novedades técnicas que disminuyeron aún más el volumen y el peso de la máquina preconizando el reloj moderno. Además de inventar el calibre Lépine y el remontaje sin llave, aplicó nuevos escapes -vírgula, cilindro- y fue uno de los primeros relojeros que empleó cajas de oro lisas, es decir, sin decoración, que rompieron con la estética de la época. Concedió gran importancia a la esfera y utilizó inicialmente cifras árabes para indicar las horas.

Curiosamente, a partir de 1775 el diámetro de las cajas aumentó y se mantuvo así hasta 1815, fecha en la que de nuevo comenzó a disminuir. A finales de siglo la técnica del esmalte traslúcido aplicado sobre una superficie metálica trabajada en guilloché revolucionó la decoración de las cajas. Líneas rectas, curvas, rayos partiendo de un eje central, escamas, etc., estos elegantes diseños se completaron

8. Se usó hasta 1830. Está integrado por una rueda de encuentro cuyo eje va provisto a menudo de un piñón de linterna que se acciona por el rodaje. Un eje vertical o varilla lleva dos paletas que reciben el impulso de la rueda de encuentro. La varilla lleva un travesaño llamado foliot que soporta dos pesas llamadas régulas. Los dientes de la rueda de encuentro actúan alternativamente en las paletas y hacen oscilar el foliot. BERnER, G.-A. Dictionnaire professionnel illustré de l'horlogerie I+II. Bienne: Federación de la Industria relojera suiza, 2002, p. 389. 
en el centro con puntas de diamantes y piedras preciosas engastadas en diseños florales y medias perlas en el borde.

Las cajas llamadas "de fantasía" se mantuvieron durante todo el siglo XVIII, aunque disfrutaron de más aceptación en el último cuarto del siglo coincidiendo con la moda Imperio. La mayoría fueron confeccionadas por relojeros suizos. Las cajas en forma de flores, de animales, de frutos, de objetos cotidianos, mandolinas, liras, arpas disfrutaron por su delicadeza y gran belleza del favor de una clientela exclusiva. Recubiertas de esmalte transparente de vivos colores permitían apreciar la decoración guilloché y combinarla con esmalte opaco y oro grabado.

Como contrapunto los relojes fabricados en Inglaterra siempre fueron más gruesos y voluminosos porque se empleó la doble caja y el remontaje, por regla general, se situó en la platina trasera. Las cajas evolucionaron poco y se diferenciaron en muchos aspectos de las francesas. En su decoración apenas se empleó el esmalte. Las cajas interiores de oro, de plata o de metal dorado solo estaban pulidas. Sin embargo, las exteriores eran mucho más recargadas predominando la rocalla y las figuras repujadas. En el centro se solía colocar una escena inspirada en la antigüedad clásica trabajada casi en bajo relieve. La luz incidía sobre ella creando movimiento y el artista jugaba así con muchos matices estéticos. Cuando el reloj disponía de sonería, el contorno de la caja se adornó con un friso calado reproduciendo motivos vegetales, en particular, hojas de acanto. Muchos de estos diseños estaban inspirados en A Book of Ornaments useful to Jewellers, Watchmakers and all other artists, publicado en 1697-1704 por Simon Gribelin II, quien se refugió en Londres huyendo de las persecuciones religiosas?. La aguja de los minutos fue introducida por Daniel Quare y Thomas Tompion para conseguir una mayor precisión en sus relojes.

Los caballeros más adinerados pudieron permitirse cajas decoradas con piedras duras -jaspe sanguino, ágata gris o marrón- y con piedras preciosas. Estas piedras se trabajaron como una lámina y se encajaron en la tapa. Además, podía enriquecerse con un diseño floral engastado con piedras preciosas en bocas cerradas o con láminas de oro caladas. Al igual que en la relojería francesa muchos de estos ejemplares se suspendieron de ricas châtelaines.

Las esferas de los relojes ingleses se elaboraron en metal cincelado y repujado. Indicaban las horas en cifras romanas y los minutos de cinco en cinco en números árabes. Una tarjeta contenía el nombre del autor. A finales del siglo XVIII la simplicidad se impuso en las esferas y las cifras horarias en números árabes desplazaron a los romanos. Los minutos se marcaron de quince en quince. Comenzaron a aplicarse esferas esmaltadas de blanco.

Por último, los relojeros suizos realizaron relojes muy similares a los franceses en parte influidos por los artífices que huyeron de las persecuciones religiosas

9. CARDInAL, Catherine. Les montres et borloges de table du musée du Louvre. La collection Olivier. Paris: Réunion des Musées Nationaux, 2000, tomo 1, p. 69. 
y se refugiaron en Suiza. Los joyeros, los montadores de cajas, los grabadores, los guillocheadores, los joyeros, los lapidarios y los esmaltadores colaboraron con los relojeros en la fabricación y decoración de las cajas. Con ellos colaboraban además los fabricantes de esferas, de agujas, los pulidores, los doradores y los fabricantes de escapes y de sonerías.

Los monarcas españoles siempre eligieron ejemplares que respondieran a las características técnicas y estéticas de estos modelos. Aunque prefirieron la precisión de los relojes ingleses no despreciaron la belleza y la exquisitez de las piezas de procedencia francesa o suiza y sus ricas cajas esmaltadas y enriquecidas con piedras preciosas. Como tendremos ocasión de comprobar en las próximas páginas en su guardajoyas se custodiaron bellas y lujosas piezas elaboradas por los principales relojeros del siglo XVIII.

\section{El RELOJ EMPLEADO COMO REGALO}

Las bodas reales y los regalos concedidos a personas cercanas a la corte incrementaron el encargo de obras exclusivas ricamente ornamentadas ${ }^{10}$. El principal comercio se mantuvo con Francia que, además, abasteció a los monarcas de vestidos, joyas y objetos de uso cotidiano.

Felipe V eligió varios ejemplares con motivo de la boda celebrada en 1722 entre el príncipe Luis -futuro Luis I- y la princesa Luisa Isabel de Orleans. Don Álvaro de Bazán, duque de Liria, gentilhombre de cámara y representante de los Reyes y del Príncipe en el momento de la entrega de la Princesa en Irún, fue el encargado de repartir varios relojes de bolsillo entre la servidumbre que acompañó a la Princesa. A cada una de las camaristas se le agasajó con un reloj adornado con diamantes. Al médico, al caballero del Rey, al mâ̂tre d' hostel de la casa del Rey, al contralor y a los pajes se les otorgó un reloj de plata a cada uno ${ }^{11}$. Años más tarde, en 1729, estos obsequios se repitieron con ocasión de la doble boda del infante Fernando -futuro Fernando VI- con la infanta María Bárbara de Braganza y de la infanta Mariana Victoria con el Príncipe del Brasil. Los relojes se compraron, por mediación del platero de oro Benito de Alfaro, al comerciante francés Florencio Kelly. A la moza de cámara de la Princesa se le concedió un reloj de repetición, de oro, con cadena y gancho tasado en 420 pesos $^{12}$ y al ayuda del guardajoyas

10. Cardinal afirma que esta costumbre fue instituida por el rey Luis XIV de Francia y que se recopiló en "Recueil des présents faits par le Roy en pierreries, meubles, argenteries et autres, à commencer en l'année 1669 jusques et compris l'année 1714». Biblioteca Nacional de París, Manuscritos franceses 14112-14113 citado en CARDINAL. Le montre..., p. 50.

11. ARANDA HuETE, Amelia. La joyería en la corte durante el reinado de Felipe V e Isabel de Farnesio. Madrid: Fundación Universitaria Española, 1999, pp. 65-66 y ARANDA HuETE, Amelia. Relojes de Reyes en la corte española del siglo XVIII. Madrid: Patrimonio Nacional, 2011, p. 25.

12. 1 peso $=15$ reales. 
que trajo las joyas de doña Bárbara otro similar, fabricado por David Hubert, con cadena, estimado en 416 pesos. Además, los Reyes reservaron varias joyas y un reloj de repetición de oro, con cadena, gancho, llave y sello, cuajado de brillantes y rubíes, para que la Princesa del Brasil lo regalase a alguien de su séquito después de la ceremonia de las entregas. Se pagaron a Kelly 2.100 pesos $^{13}$.

El marqués de Villarias, en nombre del Rey, solicitó a Juan Icotón, comerciante de París, varios relojes, sortijas, cajas y espadines con motivo de la boda del infante Felipe con Luisa Isabel de Francia ${ }^{14}$. En la relación fechada en julio de 1739 se recomendó que los objetos se ajustaran a estos precios: un reloj en 1.000 pesos; cinco relojes de oro de repetición con cadena y sello en 2.000 pesos; otro reloj de oro de repetición con cadena y sello en 400 pesos; una caja o un reloj en 300 pesos; dos relojes de oro de repetición en 800 pesos, y seis relojes de oro en 1.200 pesos. Como se aprecia el coste de los relojes variaba para poder repartirlos mejor entre la servidumbre que acompañaba a la novia ${ }^{15}$. El duque de Solferino, representante del rey Felipe $\mathrm{V}$ en el acto de entrega, regaló a la primera dama de cámara de la Infanta un reloj de repetición, fabricado en oro, guarnecido de brillantes y acompañado de cadena y sello estimado en 1.088 pesos. A las cuatro camaristas y a la dama del tocador sendos relojes de oro de repetición, con cadena y sello de 380 pesos cada uno. Al resto del séquito, maître d'hostel, dos gentileshombres y caballerizo del rey, se le entregó a cada uno un reloj de repetición de oro con la caja labrada, cadena y sello valuado en el mismo precio que los anteriores. Por último, al contralor y al capellán se les adjudicó un reloj muestra de oro con la caja cincelada y labrada apreciado cada uno en 200 pesos. A manera de reserva, por si necesitaba regalarlos en la frontera, el duque de Solferino retuvo dos relojes muestras de oro con su cadena y sello en 352 pesos y dos muestras de oro con las cajas labradas, cadenas de gancho y sello en 400 pesos $^{16}$.

El lujo que protagonizó la boda de la infanta María Teresa con el Delfín de Francia en 1744 contribuyó de nuevo a la elección de joyas y relojes para la prometida y para su séquito ${ }^{17}$. Con ocasión de este matrimonio advertimos que por primera vez se incluyó un reloj en el aderezo ${ }^{18}$ femenino que se elaboró para la

13. Archivo Histórico Nacional (en adelante AHN), Sec. Estado, leg. 2670.

14. AHN, Sec. Estado, leg. 2455.

15. Se le recomienda enviar además algunos relojes, sortijas y cajas extras por si fueran necesarios. En caso de no utilizarse se le restituirían. 1739 .

16. No se entregaron, por lo que fueron restituidos al marqués de Villarias en noviembre de

17. Casi un siglo antes, el 3 de junio de 1660, Luis XIV regaló a su prometida la infanta española María Teresa de Austria seis relojes de bolsillo guarnecidos de diamantes, esmeraldas, amatistas y otras piedras, cada uno con un lazo y cadena, sabedor del gusto de la infanta por estos objetos. AHN, Sec. Estado, leg. 2597. María Teresa introdujo en la corte francesa la moda de llevar relojes suspendidos de la cintura mediante ricas cadenas, como se aprecia en uno de sus retratos pintados por Diego de Silva Velázquez conservado en el Museo de Historia del Arte de Viena.

18. El aderezo era un conjunto de joyas que presentaban un mismo diseño. 
dote de la infanta. Se evaluó en 6.720 pesos y se ornó con diamantes tanto en la caja como en la cadena para hacer juego con el resto de las joyas. En la cadena se engastaron tres brillantes estimados en 1.060 pesos. El platero de oro y joyelero Francisco Sáez fue el encargado de engarzar los diamantes en la caja y en la cadena ${ }^{19}$. El comerciante francés Juan Kelly suministró el resto de los relojes y algunos diamantes sueltos.

Para la boda de la infanta María Antonia ${ }^{20}$, séptima y última hija de Felipe V e Isabel Farnesio, se solicitaron también a París todo tipo de géneros para confeccionar el ajuar. Para su ejecución se tuvieron en cuenta los objetos seleccionados para la dote de su hermana la infanta María Teresa. Antes de efectuarse la entrega, se redactó el consabido inventario que contenía todas las joyas que la infanta aportaba al matrimonio. El primer conjunto que se menciona es un aderezo completo, todo él engastado con 6.720 brillantes blancos, integrado por las siguientes piezas: un ramo para el pecho casi con forma de petillo; una gargantilla con una cruz; dos pendientes con arillo y tres perillas grandes; dos "pulseros» en forma de flor; dos piezas para las mangas en forma de alamares; cuatro piezas alzaderas de basquiña; una piocha grande; varios broches para falda y manto; una hebilla para la cintura y otras dos para los zapatos; dos sortijas, y un reloj de oro enriquecido con 628 brillantes distribuidos por la caja y por la cadena, trece de ellos de gran tamaño.

En la dote de la Infanta se añadieron dos aderezos más y algunas joyas sueltas. En uno de ellos, de diamantes y zafiros, se incorporó un reloj inglés con la caja y la cadena ornamentadas con setenta y tres brillantes y setenta y cinco zafiros. El otro se completó con un reloj con la caja de oro y piedra ágata o sanguina, embellecida con flores de oro cuajadas de piedras finas, entre ellas diecinueve brillantes, dieciocho rubíes y once zafiros ${ }^{21}$. La cadena era de oro, a excepción de la llave y la espalda del gancho, y estaba guarnecida con cuatro brillantes semejantes a los de la caja y sobre ellos, en dos eslabones, trece brillantes y ocho rubíes. Llevaba, también, un sello de piedra ágata. Este conjunto se amplió posteriormente con dos relojes de oro, de repetición, con cadena y sellos, fabricado uno de ellos por el relojero David Hubert. Jean Mathieu Rambaud, consejero y secretario de Estado del Rey de Saboya, certificó la entrega de estas joyas el 9 de mayo de $1750^{22}$.

Esta tradición perduró a lo largo del siglo XVIII y con ocasión de la boda del príncipe Carlos -futuro Carlos IV- con María Luisa de Parma y de la infanta María Luisa de Borbón -hija de Carlos III y hermana del anterior- con el archiduque

19. Archivo General de Palacio Real (en adelante AGP), Sec. Histórica, caja 38 y AHN, Sec. Estado, leg. 2505.

20. La infanta se casó en 1750 con Víctor Amadeo de Saboya, que se convirtió en Rey de Cerdeña en 1773.

21. Comprobamos que la descripción de ambos relojes coincide con la tipología de reloj inglés que hemos analizado en el anterior apartado.

22. AHN, Sec. Estado, leg. 2578 
Leopoldo de Austria, en febrero de 1763 se comisionó al conde de Cantillana para que adquiriese en París un reloj para la Princesa de nueva invención, con diamantes en la caja y en la cadena y de toda perfección ${ }^{23}$. Además, cuatro relojes de oro esmaltados, con diamantes en la esfera y en el botón que abría la caja, dos para señora ajustados en 18.000 reales y otros dos para caballero en 12.000 reales. Se comentó que el precio dependería del número y del tamaño de las piedras ${ }^{24}$. El conde remitió los cinco relojes el 30 de junio. La caja del reloj de la Princesa fue elaborada por el joyero francés Jacquemin. Tenía doble caja y costó 25.889 libras ${ }^{25}$.

Del guardarropa del rey Carlos III se seleccionaron por si fueran de utilidad: una muleta y un puño de oro con sendos relojes alojados en el pomo fabricados por Julien Le Roy; otra muleta de oro, a martillo, con la caña de madera de Indias y un reloj de repetición elaborado por Philipon; dos muletas firmadas por Marchan, una de ellas ornamentada con dos leones y dos relojes, y tres repeticiones más de Dutens, una enriquecida con diamantes y otra sin llave. Quedaron en reserva: un reloj de repetición para caballero con la caja de piedra engastada con diamantes y cadena de oro apreciado en 10.500 reales; cuatro repeticiones esmaltadas con cadena de oro en 10.800 reales; seis relojes de oro con cadenas de acero en 9.000 reales, y una muleta de oro con dos relojes, otra con uno y un puño de oro con reloj sin valorar ${ }^{26}$. Dionisio Lombardo compró un reloj de repetición montado en oro y piedra ónix y cadena con diamantes por 10.000 reales. El 9 de junio de 1765 se lo remitió al duque de Santisteban, mayordomo mayor de la futura Princesa, para que este lo agregase al resto de objetos que iba a regalar en Génova al séquito que acompañaba a la Princesa. Por orden del marqués de Esquilache se reunieron diez relojes más: tres en la tienda de Lumbreras, uno firmado por Graham, de oro, esmaltado, con sobrecaja a la inglesa por el que se pagaron 2.520 reales y dos, anónimos, por 4.560 reales. Otros tres en la tienda de Gomara, dos ingleses, con sobrecaja lisa por 3.000 reales y uno, de fabricación francesa, con miniaturas esmaltadas por 7.470 reales. Además, tres cadenas de acero por 36 reales. Y cuatro en la tienda de Pérez, tres elaborados por el relojero Cabrier por 10.500 reales y uno esmaltado por 2.280 reales. El duque de Santisteban obsequió a Francisco Caraves, contralor encargado de la firma de los acuerdos matrimoniales, un reloj de repetición con la caja de oro lisa, adornada con una piedra ónix y la cadena con diamantes tasado en 24.000 reales. Al médico de cámara y al cirujano les repartió, a cada uno, una muleta de oro con un reloj en el pomo. Al maestro de ceremonias de la República de Génova se destinó otra repetición de oro y a los dos capitanes y al alférez que escoltaron a la Princesa un reloj de oro a cada uno. Una vez distribuidos los presentes entre los servidores, Santisteban restituyó a Madrid: una

23. Debía ser similar al que envió para la futura archiduquesa y costar unas 25.000 libras.

24. Además, dos abanicos y el diseño de un aderezo completo.

25. AGP, Reinados, Carlos III, leg. 141.

26. AGP, Administración General (en adelante AG), leg. 770. 
repetición rica con diamantes; tres repeticiones esmaltadas; una muleta con dos relojes en la caña; otra con uno solo, y dos puños con relojes ${ }^{27}$.

A comienzos del siglo XIX, en 1802, para la doble boda, en la ciudad de Barcelona, del Príncipe de Asturias Fernando con María Antonia de Borbón-Dos Sicilias y de la infanta María Isabel con el príncipe Francisco de Nápoles, los Reyes solicitaron a París seis repeticiones muy valiosas. Todas eran de oro, con los bordes enriquecidos con dos orlas de brillantes y cadenas guarnecidas con las mismas piedras. Las dos de la infanta se apreciaron en 168.000 reales; las dos de la Princesa de Nápoles, que además se enriquecieron con rubíes, en 132.000 reales, y las dos del Príncipe de Nápoles en 144.000 reales.

Otras celebraciones familiares como el bautizo de la infanta María Isabel, hija primogénita de los reyes de Nápoles Carlos y María Amalia, celebrado el 6 de septiembre de 1740 propició que sus abuelos, los reyes Felipe V e Isabel Farnesio, regalaran a la marquesa de San Marcos, aya de la niña, un reloj cuajado de diamantes ajustado en 600 ducados napolitanos. El cardenal Acquaviva, representante del rey Felipe V en el bautizo de su nieta, fue el encargado de distribuir los obsequios entre las personas que asistieron a la ceremonia. Se dudó en agasajar a varios servidores con relojes o con cajas ya que ambos objetos estaban de moda. Al final se inclinaron por las cajas porque eran más baratas.

En 1763 la reina madre Isabel Farnesio concedió a la marquesa de Viviani un reloj de repetición guarnecido de diamantes con cadena adornada con ágatas. La Reina fue madrina del hijo que la marquesa alumbró. El comisionado que presentó la joya fue el marqués de Gamoneda. Por este motivo, Francisco de Indaburu, responsable de los fondos de la tesorería de la Reina madre, le libró una letra pagadera en Florencia por importe de 30.000 reales para que satisficiera el coste del reloj ${ }^{28}$.

Carlos III también regaló este lujoso objeto en varias ocasiones. El 9 de julio de 1771 el marqués de Montealegre ofreció, en nombre del Rey, un espadín y un bastón al hijo del duque de Castropignano por ser padrino de su bautizo. Ambas piezas estaban guarnecidas con brillantes y el bastón llevaba un reloj en el puño de oro. Los brillantes fueron engastados por el platero de oro Manuel López Sáez ${ }^{29}$. De nuevo, en enero de 1775 agasajó con un reloj guarnecido con brillantes y una sortija a su nuera María Carolina de Austria, Reina de Nápoles, que acababa de dar a luz. Al recién nacido, el príncipe Carlos Francisco, le envió un rico toisón ${ }^{30}$.

Unos meses antes, en septiembre de 1774, el monarca encomendó a López Sáez localizar en el comercio madrileño dos relojes de repetición para caballero,

27. AGP, Sec. Histórica, caja 40.

28. AGP, Reinados, Carlos III, legs. 160 y 165

29. AGP, Reinados, Carlos III, leg. 146.

30. Se había adquirido junto con el reloj un año antes al conde de Fuentes. AGP, Reinados, Carlos III, leg. 148. 
de oro, con pedrería, uno con cadena cuyo precio no debía superar los 7.200 reales y otro sin ella por 4.800 reales. Estos relojes junto con otros objetos ${ }^{31}$ deberían enviarse a Tomás Bremont, cónsul de S. M. en Marruecos, como parte de los presentes que Carlos III haría llegar al rey de Marruecos, quien, a su vez, le había obsequiado varios caballos. Halló dos en la tienda del comerciante Lumbreras, pero no se adecuaban a los requisitos del monarca pues la caja era muy sencilla, una de las tapas estaba esmaltada, la otra lucía una simple guarnición alrededor del cristal, las manos o agujas y el minutero eran de metal y la cadena de oro. Carecía de pedrería, pero era lo único que había encontrado teniendo en cuenta el precio aconsejado. Finalmente, compró al comerciante Santiago Merino un reloj de repetición guarnecido de diamantes y rubíes con la cadena de oro por 7.200 reales y otro reloj, esqueleto, con sordina, también con diamantes, rubíes y cadena de oro por 3.900 reales.

El 16 de mayo de 1776 se pagaron a Pedro Blondes 5.790 reales por un reloj de repetición, con brillantes, con cadena y tres sellos, que el Rey regaló al embajador argelino ${ }^{32}$.

Manuel López Sáez fue también el encargado de reunir un conjunto de alhajas para regalar a la familia de la reina madre de Portugal ${ }^{33}$, que regresó a Lisboa en noviembre de 1778. Además de un aderezo, tres sortijas, dos piochas, un espadín, cuatro cajas de oro y un par de hebillas recopiló seis relojes, uno de ellos encastrado en el puño de un bastón de oro con brillantes. Se tasó en 7.710 reales. El resto de los relojes de repetición con cadena en 4.200 reales, 4.080 reales, 4.020 reales y dos en 6.000 reales. Unos días más tarde tuvo que buscar otro reloj de repetición ornado con diamantes rosas, con cadena de oro y sello con la misma pedrería y una sortija de brillantes para agasajar al emisario que trajo a Madrid los regalos de la corte portuguesa. Invirtió 6.600 reales en el reloj, 2.070 reales en el sello, 840 reales en la cadena y 6.000 reales en la sortija ${ }^{34}$.

La reina María Amalia de Sajonia, esposa de Carlos III, legó en su testamento a su cuñada la princesa Electora un reloj de diáspero guarnecido de diamantes; a la princesa Cristina de Sajonia un conjunto compuesto por reloj, tabaquera y abanico de ágata adornado con brillantes, y a la princesa Isabel otro reloj cuya caja era de amatistas enriquecida con brillantes ${ }^{35}$. Su hijo, el Príncipe de Asturias, regaló a su hermano el infante Francisco Javier el 23 de junio de 1763 un valioso reloj de oro estimado en 7.500 reales.

31. Dos pistolas guarnecidas de plata, enriquecidas con diamantes y esmeraldas en la culata y una cafetera, una taza y una cucharita de oro. Para los criados que trajeron los caballos, dinero en efectivo.

32. Este a su vez quería agasajar al monarca con una escopeta y un par de pistolas.

33. Mariana Victoria de Borbón, Majestad Fidelísima, Reina Madre de Portugal y de los Algarves, hermana de Carlos III.

34. AGP, Reinados, Carlos III, leg. 150.

35. AGP, Sec. Histórica, caja 141. 
En otras ocasiones estos objetos se destinaron a gratificar a fieles servidores. La reina Isabel Farnesio premió en 1765 a Melchor Ortiz Rojano, alcalde mayor de Segovia, con una caja de oro ornada de flores ejecutada en oro de diferentes colores y un reloj de repetición, también de oro, con sobrecaja de zapa verde, en atención a las diligencias que había perpetrado para averiguar las circunstancias que rodearon el asesinato en el real sitio de La Granja de San Ildefonso de Juan Rodríguez, mozo del oficio de la furriera de la Reina. Las joyas costaron 7.500 reales $^{36}$.

Su nieto Carlos, aún Príncipe de Asturias, y sus hermanos agasajaron con un reloj a su maestro de música, Francisco Landi ${ }^{37}$. En enero de 1770 el relojero Diego Rostriaga vendió por 1.524 reales un reloj de oro con cadena de acero que se concedió al negro Genaro, que servía en las reales caballerizas ${ }^{38}$. Poco después, Carlos escogió en la tienda del comerciante Santiago Merino y Lumbreras dos relojes enriquecidos con diamantes con las cadenas esmaltadas y una caja de oro esmaltada de azul. Pagó 13.320 reales. Estos objetos se adjudicaron a los oficiales que dirigieron el 11 de julio de 1770 el ejercicio del batallón de guardias españoles que tenía su base en Vicálvaro ${ }^{39}$.

El Príncipe y el infante Gabriel regalaron al alcalde de Paracuellos una repetición de oro esmaltada que compraron el 24 de marzo de 1773 al comerciante Francisco Antonio Pérez por 2.238 reales. El alcalde les había obsequiado con dos galgos. Los criados del infante Antonio recibieron en agosto de 1779 tres relojes de oro valorados en 1.350 reales, una caja de plata sobredorada y un espadín en 480 reales. El 12 de septiembre de 1781 los Príncipes pagaron a medias, de sus respectivos bolsillos secretos, un reloj de oro, de repetición, con cadena y sellos, apreciado en 3.076 reales que concedieron al ama de una de sus hijas. El 3 de enero de 1787 se gratificó a los artífices que trabajaron en la ejecución del Nacimiento del Príncipe. Entre ellos destacaron los hermanos Domingo y José Brilli, a quienes se les agasajó con sendos relojes de oro con su cadena estimados en 2.000 reales.

Carlos IV, durante su reinado, escogió de nuevo este objeto para halagar a sus servidores. Por ejemplo, el 25 de agosto de 1789 otorgó un reloj con cadena de oro tasado en 5.000 reales al caballerizo del duque de Medinaceli que presentó al Rey tres caballos regalados por su señor ${ }^{40}$. Poco después, los tres criados del marqués de Cogolludo recibieron sendos relojes de oro con sus cadenas tras entregar al monarca varios cuadros, un servicio de porcelana y dulces remitidos por

36. Indaburu entregó el 11 de noviembre esta cantidad a Pedro de Suquilvide para saldar la cuenta. La caja costó 3.720 reales y el reloj 3.780 reales. Además, se entregaron 1.200 reales por el gasto de los ministros de la judicatura y 540 reales al escribiente a manera de gratificación. AGP, Reinados, Carlos III, leg. 161.

37. AGP, Reinados, Carlos IV Príncipe, caja 12.

38. AGP, Reinados, Carlos III, leg. 216.

39. También se le compró una repetición con la caja adornada con miniaturas y engastada por brillantes por 4.200 reales y dos cadenas de oro de varios colores por 2.400 reales.

40. AGP, Reinados, Carlos IV, Casa, leg. 125. 
el marqués. En mayo de 1792 se obsequió al picador del duque de Alcudia con un reloj de oro que costó 2.640 reales por ofrecer al Rey un caballo de la cuadra de su señor. En agosto, los criados del duque que sirvieron a los reyes durante un almuerzo fueron gratificados con tres repeticiones de fabricación inglesa de oro con su cadena correspondiente -el mayordomo Joaquín Vivas, el secretario José de Vivar y el paje Alejo Martín-, con cuatro repeticiones francesas de oro -a los ayudas de cámara Manuel Escudero, Pablo Heredia, Isidro Arce y Antonio Lópezy con una repetición de oro el guardarropa Joaquín Galeano. Un tiro de caballos rabones dio al Rey el conde de Campo de Alanje en 1793. El criado de librea del conde recibió un reloj de oro esmaltado con cadena a juego valorado en 2.400 reales. El duque de Alba envió al Rey en junio de 1794 dos caballos. Su picador los domó y fue premiado con un reloj y cadena de oro estimado en 2.440 reales.

La condesa de Ballencourt, camarera de la reina María Luisa, compró por encargo de esta en la tienda de Diego Pérez una repetición de oro con la caja guillocheada, cadena y dijes por 3.120 reales para regalar al ama de cría del infante Carlos. Más valiosa fue la repetición con la que agasajó al ama de cría de la infanta Isabel. Costó 37.000 reales. La diferencia de precio radicaba en la calidad de la pieza.

Para terminar, la ciudad de Cádiz ofreció a los monarcas una sillería y unos candeleros de plata. Los dos comisionados fueron honrados con sendos relojes, uno de repetición, de oro, esmaltado, con pedrería, tasado en 3.600 reales y el otro, una muestra de oro esmaltada en 1.920 reales $^{41}$.

\section{FELIPE V E ISABEL FARNESIO}

Felipe V no se interesó mucho por los relojes de bolsillo. Escasos son los documentos conservados en los archivos que nos permiten conocer las adquisiciones realizadas por el monarca. Una de las primeras noticias está fechada en 1713. El 4 de septiembre Juan de Goyeneche recibió de Claudio de la Roche, secretario de cámara del Rey, 6.720 reales por un reloj de oro, de repetición, fabricado en Inglaterra, con su muelle y cadena de oro que había vendido al Rey en la ciudad de Zaragoza en 1711. Thomas Hatton, relojero inglés de gran prestigio, que trabajó para el monarca durante muchos años, ejecutó sobre todo relojes de caja alta y de sobremesa. Excepcionalmente, el 9 de marzo de 1722 De la Roche le pagó 1.500 reales por un reloj de oro y 900 reales por un cuadrante de sol elaborado en bronce, ambos solicitados por el Rey ${ }^{42}$.

Unos años más tarde, el 12 de noviembre de 1737, se remitió al oficio de contralor y grefier una cuenta que ascendió a 15.368 reales y 20 maravedís por un

41. AGP, Reinados, Carlos IV, Casa, leg. 138

42. AGP, Reinados, Felipe V, leg. 462. 
reloj inglés, de oro, de repetición, adornado con miniaturas. El 17 de julio de 1739 la reina Isabel Farnesio escogió en la tienda del comerciante Juan Francisco Gozani un reloj de oro de repetición de procedencia inglesa estimado en 4.500 reales. De nuevo la Reina compró en septiembre en la tienda del comerciante Lorenzo Tarsis tres relojes de repetición de oro por 5.880 reales cada uno. Poco después, otro reloj de repetición, también de oro, guarnecido con diamantes y rubíes con su cadena por 17.520 reales y otro, con dos diamantes de gran tamaño, por 8.400 reales. Un mes después eligió otro reloj de repetición muy rico con sonería de minutos por 8.280 reales. El 9 de diciembre regaló al Rey un rico reloj de repetición, fabricado en oro, «a la última moda y primera invención", cuya sonería tocaba dos arias. Le costó 19.500 reales. El 4 de noviembre de 1740 el marqués de Scotti, mayordomo mayor de la Reina, pagó de los caudales particulares de la Reina 5.700 reales por un reloj de repetición de oro. El 24 de diciembre Juan Francisco Gozani vendió dos relojes de oro de repetición con sobrecajas adornadas con coronas de laurel por 10.200 reales. Un año más tarde, el 2 de noviembre Scotti entregó 126 reales por otro reloj de oro de repetición con un diamante en el botón, cadena y sellos. En 1743 Juan Kelly entregó una caja de oro, también elaborada en Inglaterra, para caballero, guarnecida con brillantes y rubíes que custodiaba en su interior un reloj. Solicitó por ella 14.400 reales. Por último, el 5 de abril de 1746 Tarsis le ofreció otro reloj de repetición de oro que daba los minutos por 10.800 reales $^{43}$. Como podemos comprobar tras esta larga relación, la reina Isabel Farnesio compró un buen número de relojes y siempre los consideró símbolos de lujo y distinción.

Felipe V falleció el 2 de julio de 1746. Cristóbal de Monsorín y Castelví, caballero de la orden de Santiago y asesor del Bureo, fue elegido para realizar el inventario y la tasación de todos los bienes del Rey. Destaca un pequeño reloj de oro, de perfil redondo, adornado en el borde con tres piedras. Una de las tapas estaba esmaltada en blanco y negro y llevaba engastados doce diamantes fondos, talla rosa y nueve esmeraldas muy pequeñas. El diamante mayor pesó un grano y los restantes eran de varios tamaños. La otra tapa era de oro y no estaba decorada. El oro empleado en el reloj pesó dos ochavas, dos tomines y ocho granos. El oro se estimó en 36 reales y la pedrería en 544 reales. Toda la pieza se valoró en 580 reales $^{44}$.

Tras analizar esta testamentaría comprobamos una vez más que Felipe $V$ apenas poseyó relojes de bolsillo. No sucedió lo mismo con su esposa Isabel Farnesio, quien continuó adquiriendo piezas durante su viudedad. El Rey dispuso en su testamento que su esposa percibiera una importante cantidad de dinero para sus gastos personales. Los comerciantes Florencio Kelly, Antoine Boucher, Jean Duval y Manuel Lumbreras y Merino proveyeron de relojes a la Reina viuda hasta su

43. Estas cantidades no fueron abonadas por el marqués de Scotti a los herederos de Tarsis hasta 1762. AGP, Reinados, Carlos III, leg. 160.

44. AGP, Felipe V, Registro n. ${ }^{\circ} 247$ 
fallecimiento. Por ejemplo, su tesorero pagó el 11 de octubre de 1759 a Lumbreras y Merino 3.960 reales por un reloj de oro, de repetición, con la caja grabada, fabricado por el relojero inglés Cabrier ${ }^{45}$. Unos meses después, el 5 de julio de 1760, la tesorería de la Reina madre libró a Jean Duval 39.360 reales por varias alhajas de diamantes que había suministrado en los últimos años. Entre ellas cuatro relojes de repetición valorados en 192 libras enviados en 1758. Quince días más tarde Duval recibió 11.400 reales por dos relojes de repetición. El 14 de agosto vendió otro reloj de repetición guarnecido de brillantes con su cadena por 36.000 reales. El 21 de julio de 1761 se efectuó otro pago a Duval por tres relojes de repetición: uno guarnecido de brillantes con su cadena estimado en 36.000 reales, otro en 6.000 reales y otro más sencillo en 5.400 reales.

El 12 de julio de 1762 Francisco de Indaburu, tesorero de la Reina madre, saldó varios libramientos antiguos a favor de Paula Dominga Gozani e hijos, herederos de Lorenzo Tarsis. Las alhajas elegidas habían sido principalmente abanicos, relojes y cajas. Entre ellas: un reloj de repetición, de oro, guarnecido con diamantes y rubíes y cadena a juego estimado en 292 reales; una caja de oro guarnecida de diamantes y rubíes con un reloj en la tapa en 200 reales, y cinco sellos de oro con figuras todos ellos guarnecidos con diamantes en 60 reales.

El 6 de agosto la casa de Lumbreras y Merino envió a la Reina madre un reloj de repetición para señora, con su correspondiente cadena ${ }^{46}$. Otra cuenta fechada el 18 de septiembre de 1764 nos informa que en esa fecha se entregaron al mercader italiano Octaviano Galani 6.180 reales por un reloj de repetición guarnecido de diamantes y por dos sellos para el real servicio.

La reina Isabel Farnesio falleció en 1766. Francisco Brozzetti, jefe del oficio de Guardajoyas de la Reina madre, reunió todas las joyas y alhajas para que se redactara el inventario de sus bienes. Manuel de Azpilcueta, juez nombrado para esta comisión y los representantes de sus tres hijos, Carlos III, el infante Fernando, duque de Parma y el infante don Luis, supervisaron el inventario ${ }^{47}$. Azpilcueta encomendó la tasación de los relojes a Nicolás de Penna, relojero de cámara de S. M. En esta relación fechada el 14 de noviembre se identificaron piezas importantes: un reloj simple, de oro, para señora, con cadena, guardado en un estuche negro. La caja estaba embellecida con escudos esmaltados y la sobrecaja, esmaltada, se enriqueció con un diamante pequeño. Estaba firmado por el relojero inglés Wasbourne y se valoró en 1.800 reales. Seis relojes de repetición, con cadena de oro, ganchos de metal y sellos, cinco en estuches verdes y uno en estuche negro. Este último era solo una muestra, aunque el tasador lo catalogó como repetición. Tres

45. En esa misma fecha pagó 105.000 reales por un tocador con espejo y reloj que tocaba con varias sonerías fabricado todo en Inglaterra. AGP, Reinados, Carlos III, leg. 163.

46. AGP, Reinados, Carlos III, leg. 162.

47. El representante del Rey fue Salvador de Querejazu, el del duque Francisco Solera y el del infante José Inocencio Aparici. 
de ellos estaban fabricados en Inglaterra por Ellicott. Uno era de horas, cuartos y medias, con minutero. El sello se adornaba con un camafeo embellecido con chispitas de diamantes y rubíes. Se estimó en 5.400 reales. Otro solo era de horas y cuartos dobles, en 4.200 reales. Y el tercero, con sobrecaja negra, repetía horas y cuartos. Tenía dos sellos, uno de ellos un camafeo con chispitas de diamantes. Se tasó en 2.400 reales. Otro ejemplar, con despertador, también de procedencia inglesa estaba firmado por Martinot. En el botón de la caja se incrustó un brillante pequeño. El gancho era de acero y en el sello se colocó un camafeo con chispas de brillantes y rubíes. Se apreció en 4.800 reales. Otro, de repetición sorda, de horas y cuartos, con caja de oro sin decorar, se realizó en París por Julien le Roy. Se valuó en 2.400 reales $^{48}$.

El 7 de octubre de 1766 se redactó el inventario y la tasación de los relojes que adornaban el Real palacio de Buenavista, lugar donde en ocasiones residió la Reina durante su viudedad. Aunque la mayoría eran relojes de sobremesa ${ }^{49}$, entre ellos se menciona un pequeño reloj de muestra, plano, denominado de faltriquera, con caja de oro esmaltada de azul, adornada con estrellas cuadrantes, elaboradas en porcelana. Iba acompañado de una cadena de mujer, también de oro, con el gancho de metal dorado y de un sello de ágata representando la cabeza de un negro con un collar en el cuello en el que se engastó una chispa de diamantes. Su autor era Etienne le Noir y lo fabricó en París. Penna lo tasó en 1.200 reales. Este reloj se incluyó junto con los demás en la cuenta y relación jurada que presentó Manuel Lumbreras, depositario de la testamentaría de Isabel Farnesio ${ }^{50}$. Todos los relojes que pertenecieron a la Reina madre, incluidos los de bolsillo, valorados en 82.400 reales, se pusieron a la venta en pública almoneda.

\section{FERNANDO VI y BÁRBARA DE BRAGANZA}

Fernando VI, desde su juramento como Príncipe de Asturias, demostró gran afición por los relojes de bolsillo como evidencian las numerosas cuentas que se conservan desde estos años. Al igual que su hermano Luis dispuso de una cantidad de dinero para sus gastos extraordinarios. El 8 de mayo de 1726 se adquirió por 180 reales un sello de piedra engarzado en oro para adornar la cadena del reloj del Príncipe y en el mes de agosto se pagaron al comerciante Lorenzo Tarsis 660 reales por una cadena de oro ${ }^{51}$. El 31 de diciembre de 1727 este mismo comerciante vendió dos relojes de oro, de repetición, ajustados en 4.560 reales

48. Archivo del Ministerio de Justicia, Secretaría General Técnica, Subdirección General de Documentación y Publicaciones, Archivo General, Casa Real, leg. 2, doc. 860.

49. Se incluyen relojes de sobremesa de Hatton, Julien le Roy y una Péndola Real de Graham.

50. Archivo del Ministerio de Justicia, Casa Real, leg. 31, doc. 4024. Testamentaría de la Reina. Inventario y tasación de los relojes.

51. AGP, Reinados, Felipe V, leg. 203. 
cada uno; tres muestras de oro en 1.980 reales cada una; un reloj de repetición fabricado en plata y dos muestras del mismo material en 3.600 reales, y varias cadenas de hombre y de mujer en 5.880 reales. Y el 15 de abril de 1734 recibió 7.080 reales por otro reloj de oro con repetición de minutos. En la memoria de los gastos causados en el guardarropa del Príncipe fechada el 10 de febrero de 1735 se incluyó el libramiento de 7.529 reales y 7 maravedís por un reloj de repetición de oro firmado por Graham. Juan Kelly fue otro de los comerciantes que suministró relojes al Príncipe y a otros miembros de la familia, como hemos comprobado. El 12 de abril se libraron a su favor 30.000 reales por un reloj de repetición, de oro, guarnecido de brillantes y rubíes con una cadena grande. El 16 de enero de 1737 Lorenzo Tarsis cobró 5.700 reales por un reloj adornado con una piedra oriental de jaspe y cadena con brillantes y rubíes y 1.800 reales por una caja de oro en forma de barco. El 9 de febrero se entregaron 3.268 reales por un reloj de minutos del maestro Graham.

El 3 de julio el tesorero Miguel Francisco de Aldeoca libró una cuenta a favor del platero Juan de Romeral por valor de 20.088 reales y 16 maravedís por varias alhajas elegidas por el príncipe. Entre ellas se encontraba un reloj de oro de la tienda del mercader Juan Francisco Gozani estimado en 132 pesos. El 12 de octubre Romeral presentó otra cuenta en la que incluyó dos relojes de repetición fabricados en oro, uno valorado en 5.700 reales propiedad de Juan Kelly y otro en 4.400 reales de Lorenzo Tarsis. El 6 de marzo de 1738 este último comerciante vendió varios relojes y cadenas guarnecidas de pedrería y el 12 de diciembre de 1739 cobró 27.000 reales por un rico reloj de repetición, con sonería de minutos, adornado con una piedra oriental y cadena de señora enriquecida de diamantes y rubíes. Ese mismo día percibió la misma cantidad por otro reloj de repetición, también para señora, con la cadena adornada con flores cuajadas de brillantes y 12.000 reales por otro ejemplar, que daba las horas y los cuartos y tenía despertador. De nuevo, Tarsis el 26 de enero de 1741 percibió 5.100 reales por un reloj de repetición, con la caja de oro, fabricado por David Hubert. En la memoria de los gastos causados en el guardarropa del Príncipe en junio de 1741 se mencionó un reloj del relojero inglés Graham estimado en 3.320 reales y 14 maravedís y otro reloj de minutos, con cadena y sellos en 7.500 reales escogidos en la tienda de Juan Kelly. Unos meses más tarde, se abonaron dos relojes más procedentes de Inglaterra, uno del relojero inglés Ellicott y otro de Ferron ${ }^{52}$. El 18 de julio Kelly cobró 8.220 reales por un reloj "que da los 14 minutos» con su cadena, gancho y sello y 840 reales por dos sellos de cornelina, uno representando la cabeza de Minerva y otro la de Venus. El 14 de noviembre Martín de Casanave trasladó a Madrid un reloj de Marcos y Juan Weylan desde Londres y el 8 de enero de 1742 envió vía París otro reloj de repetición de oro fabricado por David Hubert también en Londres ${ }^{53}$.

52. El de Ellicott costó 2.846 reales y 4 maravedís. El de Ferron no está valorado.

53. AGP, Reinados, Felipe V, leg. 199. 
El 24 de marzo de 1742 Miguel Antonio de Zuaznavar, ayuda de cámara y jefe de su Guardarropa, pagó 13.200 reales por una repetición, con despertador, sonería de horas y cuartos, fabricada por Ferron; 1.620 reales por tres sellos que representaban figuras, y 180 reales por otros dos sellos de oro. En mayo otras 410 libras por una caja de reloj, de oro guilloché, vidrio de cristal de roca custodiada en una caja de zapa con charrera de metal dorado que se envió desde París. En agosto encargó que se comprara en Londres un reloj de oro, del maestro Graham, y que se enviara al marqués de San Gil, embajador de La Haya, para que este a su vez lo remitiera a Madrid vía Ámsterdam. El reloj no era de repetición, tenía la caja lisa y el cuadrante blanco. Costó 3.277 reales y 6 maravedís, incluidos los gastos del envío. El 25 de septiembre el tesorero del Príncipe satisfizo al relojero de cámara Fernando van Ceulen y Zaldívar 3.011 reales y 26 maravedís por un reloj de oro que ejecutó para el Príncipe ${ }^{54}$. Este es uno de los pocos encargos realizados a un relojero de cámara.

El 8 de junio de 1743 Juan Kelly remitió una caja de oro que contenía un reloj por 14.400 reales. Zuaznavar realizó varios pagos más relacionados con relojes en los últimos meses de 1744: el 22 de septiembre 4.279 reales por una repetición, de oro, fabricada por el relojero Martineau, que trajo desde Portugal el pintor Simón Pedro de Gama; el 16 de diciembre 2.640 reales por otra, con la caja fabricada en oro, elaborada por el relojero inglés Daniel Quare; el 22 del mismo mes 960 reales por un reloj de muestra del mismo relojero inglés proporcionado por el relojero de cámara Fernando van Ceulen y Zaldivar, y el penúltimo día del año 4.800 reales a Juan Francisco Gozani por otro reloj de muestra, muy pequeño, de oro, con la caja de diáspero guarnecida de diamantes y 480 reales por cuatro sellos de oro.

Siempre nos ha parecido curioso el gusto que el monarca demostró por los bastones con relojes encastrados en el pomo. Ya en noviembre de 1741, siendo aún príncipe, adquirió a Lorenzo Tarsis un ejemplar con el puño de oro guarnecido de diamantes, esmeraldas y rubíes que llevaba alojado un reloj. Pagó por él 9.600 reales. Poco después de su proclamación, en febrero de 1747, el marqués de la Ensenada comentó al duque de Huéscar, embajador español en París, que no enviara más bastones con el puño de oro o de porcelana, sino que, en adelante, escogiera los que llevaran un reloj encastrado en el pomo porque estos eran los favoritos del monarca. Tal era la afición que su esposa la reina Bárbara de Braganza eligió estas piezas como regalo de santo, de cumpleaños y de fechas señaladas. Por eso, el 20 de diciembre Huéscar envió un reloj fabricado por Julien le Roy alojado en una muleta con el puño de oro grabado. Se valoró en 1.231 libras y 14 sueldos $^{55}$. El 9 de septiembre de 1748 Ricardo Wall, embajador de España en Londres, recibió el encargo de encomendar a Pierre Dutent la ejecución de un puño de bastón guarnecido de diamantes con un reloj encastrado. Desde Madrid

54. AGP, Reinados, Felipe V, leg. 297.

55. AGP, Reinados, Fernando VI, caja 102. 
temieron que el relojero escogido, Ellicott, no entregara el reloj a tiempo. Por eso recomendaron a Dutent que solicitara otro reloj similar al maestro Graham. También le aconsejaron que comprobara que la caña tuviera la medida adecuada respecto a la altura del monarca. Este mismo día también se le confió que solicitara a alguno de estos dos maestros la fabricación de una muleta con un reloj a cada lado. Pero como ambos estaban muy ocupados, para evitar retrasos, eligió a un discípulo del maestro Tompion. Este realizó dos modelos en plomo de diseño diferente para comprobar cuál era el más idóneo.

Como ambos embajadores habían recibido la comisión de remitir a Madrid todos los relojes de nueva invención que descubriesen a la venta, tres meses antes, el 26 de septiembre, Ricardo Wall informó que había localizado en el comercio de un bijoutier un reloj que adornaba su caja con un diamante blanco, otro azul y dos pequeños de color rosa tasado en 1.200 libras. Desconocemos si fue comprado por el Rey. Casi dos años después, el 11 de mayo de 1750 se solicitó al relojero francés Baillon que ejecutara un reloj de faltriquera, de repetición, con segundos y campana, chato y con la esfera blanca. El relojero comentó que no podía construirlo tan plano por el tamaño de la campana. Pero, ante la insistencia del monarca y la posibilidad de que se encomendara el reloj a otro relojero, no solo consiguió reducir el tamaño, sino también colocar un muelle que detenía el movimiento mientras se le daba cuerda. Poco después se le confió la ejecución de un reloj que encajara en el chatón de una sortija.

Como ya hemos comentado en otra publicación ${ }^{56}$, Britten, Baillie y Cardinal afirman que Fernando VI encargó al inglés Thomas Mudge un reloj de gran complicación. Le dejó libertad para elegir las complicaciones que más le interesaran. Mudge envió un reloj cuyo movimiento encastró en el pomo de un bastón. Indicaba el tiempo real y el tiempo aparente, daba las horas y poseía sonería de repetición de horas, cuartos y minutos. El Rey le pagó 480 guineas. Cardinal publica una fotografía del reloj realizado por Thomas Mudge y vendido al Rey de España el 22 de agosto de 1755 , dotado de dos espirales y un dispositivo bimetálico para la compensación térmica. Actualmente se conserva en The Clock Room de la Guildhall Library de Londres, n. ${ }^{\circ}$ inv. $189^{57}$. Pero de este encargo hasta el momento no hay constancia documental en el Archivo General de Palacio Real y al conservarse el reloj en un museo londinense no podemos ratificar que el reloj fuera enviado al monarca.

\section{CARLOS III}

Cuando aún era infante de España, Carlos adquirió al comerciante Florencio Kelly un reloj de repetición, fabricado en oro, con cadena a juego. Gaspar de

56. ARANDA Huete. Relojes de reyes..., p. 57.

57. CARDinal. La montre..., p. 62. 
Montoya, tesorero del Príncipe y de los infantes, despachó el 19 de mayo de 1729 un libramiento a su favor por importe de 342.180 reales. En esta cantidad también se incluyó el precio de un espadín de oro guarnecido de brillantes y de dos pares de botones para puños de camisa enriquecidos con cuatro brillantes. Solo se le pagaron a cuenta 30.000 reales $^{58}$.

Ya Rey de España, el comerciante Jean Duval le vendió el 8 de abril de 1760 un reloj ornado con diamantes custodiado en un estuche de piel. Cobró por él 12.000 reales. A finales de junio de 1762 este mismo comerciante ${ }^{59}$ comentó en una carta remitida al marqués de Esquilache que había encomendado al relojero "más hábil» de la ciudad la ejecución del reloj de repetición a minutos y la cadena de oro que le había encargado unos días antes. El 19 de septiembre el marqués de Grimaldi agradeció a Pedro Gil de Olondriz el envío de otro reloj.

A principios del mes de enero de 1763 se solicitó a los Duval cuatro repeticiones adornadas con brillantes, "a la última moda, perfección y buen gusto", con sus correspondientes cadenas de oro; dos para dama cuyo precio debía rondar los 500 pistolas -30.000 reales-, y otras dos para caballero por 300 pistolas -18.000 reales-. Además, varias cajas de tabaco, dos abanicos, diamantes sueltos y el dibujo de un collar. El 21 de febrero Jean remitió una carta en la que informaba que estaba intentando reunir estos objetos. En junio, junto con varias partidas de brillantes, una flor para el pecho, un abanico y una caja esmaltada, envió dos repeticiones con las cajas elaboradas en ágata, una para dama estimada en 30.000 reales, otra para caballero en 21.000 reales y dos cadenas de oro para caballero en 1.200 reales. Se le restituyó porque no debieron agradar al monarca: un reloj con escape de cilindro guarnecido de brillantes tasado en 12.000 reales; un conjunto integrado por una repetición con cadena, perfumadores y tabaqueras enriquecidas con amatistas y brillantes en 60.000 reales; otra repetición para señora con caja de ágata y brillantes y cadena de brillantes en 30.000 reales, y otra similar para caballero, pero sin cadena, en 21.000 reales. El 14 de junio presentó la factura en la que también incluyó: un reloj adornado con diamantes y tapa de cristal por 12.000 reales; otro reloj de repetición con cadena de oro y cuatro relojes de repetición con la caja realizada en piedra ónix y la cadena enriquecida con brillantes, dos de ellos para señora y los otros dos para caballero. Comentó que había elegido las piezas según el gusto inglés ${ }^{60}$.

58. El infante marchó a Italia dejando sin pagar parte de sus gastos. Años después, y tras la reclamación de Kelly, esta deuda pasó a engrosar los débitos incluidos en la testamentaría del rey Felipe V, padre de Carlos. En 1760 su hijo Juan Kelly aún reclamaba esta cantidad porque todavía no le habían pagado. Finalmente, el 31 de julio de 1760 cobró de la tesorería general la suma adeudada. AGP, Reinados, Carlos III, leg. 137.

59. En realidad, eran dos hermanos, Pierre y Jean, pero el interlocutor solía ser Jean.

60. AGP, Reinados, Carlos III, leg. 140. 
Pedro Chevalier, platero de cámara, fabricó en junio de 1765 la caja de un reloj en piedra oriental, posiblemente jade, con cadena de oro custodiada en un estuche por 9.000 reales $^{61}$.

Los encargos y las compras se sucedieron. El 14 de julio de 1774 la tesorería mayor pagó, por real orden, a José Ortiz 11.346 doblones y medio por varias joyas $^{62}$ y por un reloj de señora que habían pertenecido al conde de Fuentes. El reloj se valoró en 1.600 doblones, pero se retasó en 1.144 doblones. El tasador, Manuel López Sáez rebajó el precio de las joyas y recomendó que no se adquiriese el reloj porque "tenía difícil acomodo". Pero como formaba parte de un conjunto y el conde necesitaba el dinero, al final su compra se justificó porque, o bien se podía utilizar para un regalo, o bien se podían desmontar los brillantes de la caja y de la cadena porque eran de buena calidad y emplearse en la ejecución de otra pieza ${ }^{63}$.

El 5 de agosto de 1780 Ferdinand Berthoud, uno de los mejores relojeros franceses como ya hemos comentado, famoso por construir relojes de gran precisión y cronómetros marinos, fabricó para el Rey un movimiento de repetición colocado en una sencilla caja de oro, sin decorar, por el que solicitó 4.884 reales. Un año más tarde, envió otro reloj de repetición, de oro, con la cadena adornada con pequeñas perlas. Costó 6.420 reales.

Pedro de Lerena, ministro del despacho universal de Hacienda, recibió de la tesorería general a mediados de 1785 una cuenta por los gastos en alhajas del rey Carlos III en los últimos meses. Además de incluir las joyas regaladas por el Rey a su nieta la infanta Carlota Joaquina posiblemente con motivo de su boda con el príncipe Juan VI de Portugal, se mencionan varias joyas ${ }^{64}$ y dos relojes con sus cadenas de brillantes apreciados en 90.000 reales.

El conde de Floridablanca, en nombre del Rey, solicitó el 6 de marzo de 1786 a Pedro de Lerena y este a su vez al comerciante Manuel de Ribas Albear dos relojes de bolsillo guarnecidos de brillantes. El precio de cada reloj no debía sobrepasar los 6.000 reales. En la factura presentada por el comerciante uno de los relojes se describe como un reloj de oro, guarnecido de diamantes con su cadena a juego tasado en 4.440 reales y el otro similar, pero con sello guarnecido también de diamantes por lo que el valor aumentó a 6.300 reales. En total, 10.740 reales. El

61. AGP, Reinados, Carlos III, leg. 142.

62. Los del toisón se tasaron en 3.911 doblones; los de la placa de la orden del Espíritu Santo en 3.580 doblones; los de la presilla y su botón en 590 doblones; los de la cruz pequeña de la orden del Espíritu Santo en 432 doblones; los de las hebillas en 933 doblones, y los de la venera en 1.100 doblones. En total 12.146 doblones, pero se hizo una rebaja porque el tasador afirmó que no valían esa cantidad. AGP, Reinados, Carlos III, leg. 147.

63. Al final, como hemos visto en páginas anteriores, el reloj y el toisón se regalaron a la reina María Carolina de Nápoles y a su hijo el príncipe Carlos Francisco.

64. Entre las joyas: un joyel con retrato, un toisón, un aderezo en blanco, otro aderezo de esmeraldas y brillantes, diez cajas con esmaltes y brillantes, cuatro sortijas con brillantes y una presilla para sombrero. AGP, Reinados, Carlos III, leg. 155. 
14 de junio Lerena adquirió para el Rey en Aranjuez, de nuevo a Manuel de Ribas, un reloj de oro para señora con cadena guarnecido de diamantes y otras piedras finas por 6.360 reales y un par de broches también de brillantes para señora por 7.200 reales. En total, 13.560 reales. Recibió esta cantidad, en su nombre, su hermano Andrés de Ribas Albear.

Todos estos libramientos, tanto los de este reinado como los efectuados en los años anteriores, evidencian un alto volumen de adquisiciones. Los monarcas encargaron estos objetos en el extranjero y pagaron elevadas sumas en parte por los gastos de aduana y traslado. La sociedad cortesana imitó el gusto de la real familia y también gastó grandes cantidades de dinero en comprar estas piezas en el extranjero. Por eso, desde el reinado de Felipe V se promocionó el establecimiento de manufacturas relojeras en el ámbito nacional y la creación de escuelas de relojería que formaran a los relojeros españoles para que pudieran fabricar relojes de bolsillo y surtir de estos objetos a la clientela deseosa de poseerlos. Tras varias iniciativas fallidas, el 5 de julio de 1770, la Junta General de Comercio y Moneda informó al rey Carlos III que unos relojeros franceses instalados en Madrid, los hermanos Philippe y Pierre Charost, solicitaban permiso para abrir una fábrica-escuela de relojería en la capital. Ofrecían su talento para formar y enseñar el arte de la relojería a una docena de jóvenes durante un período de aprendizaje de siete años.

Al principio la propuesta fue del agrado del monarca porque al existir esta gran demanda, agravada en parte al imponerse en la indumentaria femenina y masculina la moda de lucir dos relojes suspendidos de una chatelaine, la fábricaescuela podía abastecer de estos objetos al público interesado y competir con el comercio extranjero. Además, por primera vez se quería instituir en España una legislación que controlase el arte de la relojería. Los Charost se comprometieron a enseñar a los aprendices a construir relojes de bolsillo o faltriquera. El examen para alcanzar el grado de maestro consistía en elaborar un reloj de bolsillo y para estimular el aprendizaje se convocaron premios para los mejores aprendices. En la escuela se fabricaron relojes sencillos, con cajas de oro y plata, algunas esmaltadas y los primeros relojes de bolsillo tipo esqueleto, es decir, con caja calada que permitía ver la maquinaria ${ }^{65}$. Las mujeres comenzaron a incorporarse al mundo laboral especializándose en la elaboración de las esferas esmaltadas y de las cadenas. Pero como ya hemos comentado en otras publicaciones ${ }^{66}$, la escuela-fábrica fracasó porque los hermanos Charost no cumplieron con lo prometido.

La testamentaría de Carlos III es también un buen instrumento para conocer los relojes de bolsillo que poseyó el monarca. La descripción de sus cajas, de oro y plata, esmaltadas o grabadas y enriquecidas con piedras preciosas, demuestra

65. Uno de estos relojes, con caja de oro, fue adquirido por el platero de oro Leonardo Chopinot.

66. ARANDa HuETE. Relojes de reyes..., pp. 68-78. 
una vez más el carácter lujoso de estos objetos ${ }^{67}$. Destacan por su riqueza: una repetición, a segundos, en caja de oro adornada con una cifra esmaltada de azul y guarnecida con dos diamantes fabricada por Julien le Roy y tasada en 3.600 reales; otra del mismo autor, caja de fantasía en forma de concha en 2.400 reales; otra repetición de Baptiste Baillon con la caja esmaltada con una cifra guarnecida de brillantes y rubíes en 4.872 reales; otra del mismo autor con la caja esmaltada reproduciendo motivos florales azules y ocres en 3.000 reales; otra de Ellicott con la caja esmaltada guarnecida con un círculo de diamantes en 7.390 reales; otra de Cabrier adornada con la cifra del rey esmaltada en azul y un diamante en el botón en 6.000 reales; una muestra de Martineau con la caja esmaltada y adornada con brillantes valorados en 19.400 reales, y un relojito de autor desconocido en caja de oro cincelada guarnecida con diamantes, esmeraldas, zafiros, cornalinas y dos perlas valorado por el platero Leonardo Chopinot en 10.695 reales, de los cuales 9.495 reales correspondían a la caja.

\section{Carlos IV y María Luisa de Parma}

Carlos, al igual que su padre y que su tío Fernando, comenzó a adquirir relojes desde su juventud. La mayoría, como en reinados anteriores, fueron suministrados por los comerciantes madrileños y otros escogidos por los embajadores de Londres y París. Casi ninguno fue ejecutado por los relojeros de cámara, aunque estos si examinaban la calidad de las piezas presentadas. El 30 de marzo de 1763 el relojero de cámara Simón Martínez le ofreció un reloj de repetición fabricado por el maestro Graham que estaba valorado en 4.200 reales. Unos días más tarde, el 11 de mayo, el tesorero del giro de Londres, Miguel de Ventades, adquirió para el Príncipe en la capital inglesa un reloj de oro firmado por Ellicott apreciado en 2.788 reales y 13 maravedís. Una vez más comprobamos la predilección del Príncipe por la relojería inglesa porque, aunque sus cajas eran más sencillas, sus máquinas eran más precisas que las francesas. Del maestro Ellicott, uno de los mejores relojeros ingleses como ya hemos visto, también poseyó otra repetición de bolsillo elegida por su jefe de la Real Guardarropa, Esteban Zuaznábar, quien la compró en el mercado madrileño por 4.800 reales. El mismo precio costaron dos muestras de oro, de repetición, del mismo autor proporcionadas una vez más por Martínez.

Entre las cuentas de los gastos extraordinarios del Príncipe y de los infantes hay una fechada el 30 de julio de 1765 de la tienda Gomara y Compañía en la que se menciona un reloj con forma de pistola estimado en 75 reales $^{68}$. En otra factura presentada un año más tarde por el comerciante José Geniani se incluyó un reloj

67. FERNÁNDEZ-Miranda y LOZANA, Fernando. «Inventarios Reales, Carlos III, 1789-1790, Madrid, 1989. No nos vamos a detener en ellos porque ya los estudiamos». En ARANDA HuETE. Relojes de reyes..., pp. 84-87.

68. En total la factura ascendió a 2.254 reales. AGP, Reinados, Carlos IV Príncipe, caja 44. 
con la caja fabricada en ágata y oro, guarnecido con diamantes y otras piedras por el que se pagaron 5.060 reales y una repetición de oro con la esfera bordeada de diamantes por 3.960 reales.

El comerciante Francisco Antonio Pérez, con tienda abierta en la puerta del Sol, ofreció el 3 de julio de 1770 a la princesa María Luisa de Parma un reloj de oro francés, de repetición, guarnecido de diamantes por 14.542 reales. Un año después, los Príncipes le compraron un reloj de oro con la caja lisa fabricado por Cabrier por 1.680 reales y una muestra de oro por 2.560 reales. En abril de 1773 Juan Baptiste Lecouflet entregó dos relojes de oro, uno de ellos firmado por Lépine, para uso de los Príncipes.

Las adquisiciones de relojes de bolsillo por parte de los Príncipes, durante estos años, no cesaron debido al capricho que siempre sintieron ambos por estos objetos. El 13 de julio de 1777 eligieron en el comercio madrileño un reloj de repetición, de oro, para mujer, inglés, esmaltado y con su cadena guarnecida con 925 diamantes brillantes. Les costó 32.640 reales. En noviembre de 1779 seleccionaron otro, francés, de oro, con la caja esmaltada de azul y dos sellos de oro por 4.560 reales. El comerciante Pérez les vendió el 1 de agosto de 1781 por 6.420 reales un reloj de oro, de repetición, fabricado por el maestro francés Ferdinand Berthoud con su cadena adornada con pequeñas perlas.

Algunos comerciantes de provincias y extranjeros, conocedores del gusto de los Príncipes por estos lujosos objetos, les remitieron piezas exquisitas. Cristóbal Vilella, proveedor de objetos de arte italianos a través de los puertos de Mallorca y de Menorca, proporcionó a la Princesa en julio de 1785 un reloj de oro de pequeño tamaño que tocaba tres danzas al que se le añadió un minuet con repetición para que sonara cada hora. El reloj, que lo había comprado al veneciano Alexandro Comlenovich, costó 4.800 reales. El minuet fue fabricado por Francesco Canobbio y se pagaron por él 200 reales. El mayor proveedor fue el francés François-Louis Godon, con tienda abierta en París. Suministró con regularidad a Carlos y María Luisa, primero como Príncipes y luego como Reyes, relojes y objetos de lujo hasta su fallecimiento en 1800. Ya hemos estudiado su figura en otras publicaciones, pero destacaremos algunas piezas significativas. En una carta afirma: «'ai reçu de monsieur de Viergol la somme de huit mil reaux pour valeur de la montre a repetition perpetuel que j'ai fournie a S.A.R. le prince des Asturies. Madrid le 4 mai 1786. Godon ${ }^{69}$.

Tras su proclamación como reyes los encargos aumentaron. El 21 de agosto de 1789 Carlos Ruta, jefe de la Real Guardarropa de S. M., pagó a Josef Opoix 12.000 reales por un reloj de oro damasquinado adquirido por el Rey ${ }^{70}$. Al año siguiente, Godon presentó el 20 de agosto una factura en la que incluyó un reloj de nueva construcción con la cifra del Rey y el retrato de la Reina "con dos maneras

69. AGP, Reinados, Carlos IV, Príncipe, caja 2.

70. AGP, Carlos IV, Cámara, caja 32. 
de segundos, naturales y artificiales pudiéndose fixar la Grande... parar la pequeña, obra curiosa i la más seguridad para observaciones». A finales de año entre otros objetos llegaron a Madrid: una sortija con divisa, reloj y un secreto para poner un retrato tasada en 2.800 libras; un reloj de repetición con la caja esmaltada, con campana y segundos fijos en 1.850 libras; otro, en cuya caja se podía colocar un retrato, en 1.610 libras, y otro esmaltado, chato, en 750 libras.

En 1793 otra factura reúne varios relojes: uno con cuatro muestras y las fases de la luna valorado en 13.600 reales; otro de repetición con cinco muestras, calendario, segundos fijos y caja esmaltada en 12.400 reales; otro similar y con la caja esmaltada representando varias figuras en 13.600 reales; otro, pequeño, adornado con perlas y esmeraldas en 5.400 reales; otro de repetición, con segundos, guarnecido con perlas finas en 12.800 reales; otro, de repetición, con sonería de horas, cuartos y minutero y enriquecido con perlas en 15.800 reales, y una sortija con un reloj ovalado en el chatón con brillantes en el cerco y un secreto en 16.400 reales $^{71}$. Observamos cómo va cambiando el estilo y la decoración de las cajas y cómo se van incluyendo en los envíos relojes de gran complicación dotados de los nuevos avances técnicos aplicados a la relojería de bolsillo por los relojeros franceses.

En julio de 1796 Godon envió de nuevo desde París varios relojes de gran complicación. Sirva a manera de ejemplo uno, con caja esmaltada, en cuya esfera en cinco muestras se podían observar las fases de la luna, los segundos, los terceros, el calendario y el semanario. Las cifras de los reyes adornaban su caja. Solicitó por él 14.000 reales.

Paulina Junquera informa ${ }^{72}$ de la construcción por el relojero español Manuel Gutiérrez de dos relojes de bolsillo, uno fabricado para el Rey y el otro para la Reina. El del Rey tenía todas las piezas guarnecidas de oro y el de la Reina llevaba inscrito su nombre y grabada la corona real. Ambos relojes fueron presentados en 1797.

François-Louis Godon falleció el 17 de enero de 1800. Su viuda, hábil comerciante y sabedora del interés que sentían los monarcas por estos objetos, remitió a la corte española un reloj saboneta n. ${ }^{\circ} 264$ valorado en 2.200 reales; un reloj con la caja esmaltada y carillón en 8.000 libras; otro por el mismo precio, también esmaltado y adornado con pequeñas perlas; otro con dos cercos de perlas finas en 7.250 libras; uno, de repetición, con perlas grandes en 5.000 libras, y otro de invención moderna, grabado y esmaltado, en 1.600 libras. Estos relojes respondían claramente a la moda imperante en estos momentos en Europa. En noviembre ofreció a la Reina un reloj de faltriquera con juego de flautas que tocaba música española y que podía adornarse con brillantes; otro con la caja en forma de corazón con música de

71. AGP, Reinados, Carlos IV, Casa, leg. 182

72. Junquera, Paulina. Relojería palatina. Antología de la colección real española. Madrid: Biblioteca Literaria del relojero, Ed. Roberto Carbonel Blasco, 1954, p. 60. 
campanas que sonaba cada hora, y otro, con ecuación, lo que indica que a la Reina no solo le interesaban la belleza y la diversión, sino también la precisión.

Curioso es un reloj denominado de cacería. El Rey adquirió un ejemplar. Era de repetición, con timbre, calendario, escape libre y compensador. La caja estaba esmaltada y tenía doble fondo. Costó 3.400 libras. Carlos IV siempre se interesó por las novedades que podía comprar en el mercado, por los avances técnicos aplicados a las máquinas y por la moda en la decoración de las cajas. Por eso el cónsul Fernando de la Serna informó desde París que había encomendado la construcción de dos relojes de faltriquera a la última moda, con las cajas embellecidas con brillantes, de acuerdo con las normas dictadas por S. M. El monarca había seleccionado el diseño, elegido el número de brillantes y el tamaño y la talla de los mismos. Uno de los relojes debía costar un tercio más que el otro y tenía de plazo 25 días para remitirlos a Madrid.

Como hemos comentado, a finales del siglo XVIII causaron furor los relojes de fantasía. La Reina poseyó varios enviados todos ellos desde París. El 11 de mayo de 1803 el comerciante Juan Bautista Terón vendió a la Reina varios ejemplares curiosos: uno con la caja en forma de tulipán estimado en 1.900 reales y otro con forma de concha en 1.300 reales. Además, también le ofrecieron: otro con forma de sombrero por 2.640 reales, otro representando un pavo real por 2.640 reales y dos con forma de violines por 4.800 reales.

Dos importantes relojeros franceses sobresalieron en estos últimos años del siglo XVIII y ambos trabajaron para los monarcas españoles: Jean-Antoine Lépine y Abraham-Louis Breguet. Lépine vendió el 5 de abril de 1802 un reloj de oro guarnecido con diamantes estimado en 38.400 reales, otro enriquecido con piedras preciosas en 9.000 reales y una repetición grande que daba las horas y los cuartos en 8.000 reales. Fernando de la Serna envió dieciocho relojes fabricados por Lépine. Los Reyes eligieron cuatro: uno embellecido con tres orlas de brillantes, el fondo mate adornado con la cifra coronada del Rey y cadena con brillantes apreciado en 283.392 reales; otro con la caja adornada con una roseta egipcia y tres cercos de brillantes en 160.031 reales, y dos repeticiones, una de ellas con una miniatura que representaba a Cupido, en 7.200 reales cada una. Lépine envió poco después otros catorce relojes para que los monarcas los examinaran sin compromiso. En diciembre de 1805 ofreció a la Reina una muestra de faltriquera o repetición de oro con escape libre, montada sobre rubíes y a compensación que acababa de construir. Solicitaba por ella 150 luises.

En cuanto a Abraham-Louis Breguet ${ }^{73}$, quien ya había ejecutado para la Reina en 1799 un reloj de sobremesa tipo simpático, presentó el 5 de agosto de 1802 una factura que ascendió a 26.484 libras tornesas por cinco relojes guarnecidos con

73. Gracias a su amigo Agustín de Bétancourt, Breguet consiguió introducirse en el mercado español. Breguet, Emmanuel. Breguet horloger depuis 1775. Vie et postérité d'Abraham-Louis Breguet (1747-1823). Paris: Alain de Gourcuff Éditeur, 1997, pp. 202-206. 
brillantes, con escape de cilindro, centros de rubíes y compensación térmica ${ }^{74}$. Uno de los modelos más característicos de este prestigioso relojero fue el tipo ciego o de tacto que permitía conocer la hora sin necesidad de mirar la esfera, solo gracias al tacto. La Reina disfrutó de varios, como un ejemplar n. ${ }^{\circ} 14.783$, con doble fondo, la caja adornada con una miniatura y guarnecido de brillantes valorado en 22.260 reales; otro con el n. ${ }^{\circ} 14.789$ con la caja grabada en 6.120 reales; otro n. ${ }^{\circ} 14.786$ con doble fondo, grabado y embellecido con marfil por 6.600 reales, y otro más sencillo, n. ${ }^{\circ}$ 14.787, por 6.420 reales. La caja de estos relojes solía lucir una flecha cuajada de diamantes o de perlas como el ejemplar vendido por mediación del platero de oro Juan Soto por 5.600 reales. El tesorero real le entregó el 3 de enero de 1806 por orden del Rey 2.640 libras por dos relojes, uno de oro con una sola aguja, escape de cilindro y centros de rubíes, registrado con el n. ${ }^{\circ} 1.695$, y otro, más pequeño, con el n. ${ }^{\circ}$ 1.282, también con una sola aguja, la caja de oro guillocheada, la esfera esmaltada y dorada, escape de cilindro y centros de rubíes ${ }^{75}$.

Por último, la reina María Luisa adquirió en el comercio madrileño varios relojes de pequeño tamaño para lucirlos suspendidos del cuello mediante una cadena - moda que como hemos visto se impuso a principios del siglo XIX-, otros encastrados en el chatón de una sortija -uno de ellos estaba rodeado de una trenza de pelo anticipándose a la moda romántica- y otros completándose con autómatas -con dos pequeñas figuras realizadas en oro dotadas de movimiento que golpeaban a las horas dos campanas situadas encima de la esfera-. Un curioso ejemplar encarnaba la figura de la samaritana y tocaba ocho sintonías. Costó 16.000 reales. Otro, la figura de una bailarina que danzaba al compás de la música, por 5.900 reales, y otro, un chino que surgía de una gruta para tocar las horas retornando a ella cuando terminaba, por 15.000 reales.

En las cuentas del bolsillo secreto de la Reina se registraron muchos relojes más que la soberana debió llevar con ella al exilio junto con sus joyas y otros objetos de valor. Gracias a los inventarios realizados de sus bienes el 28 de julio de 1800 y el 1 de enero de 1807, ya estudiados en profundidad en otra publicación ${ }^{76}$, conocemos los relojes de bolsillo de la Reina depositados en su Real Guardajoyas en ocho papeleras.

Tras analizar las fuentes documentales conservadas en los archivos nacionales podemos comprobar como los monarcas españoles disfrutaron de un buen número de relojes que respondían perfectamente a los modelos propios de la época. Los consideraron siempre un objeto de lujo y al estar fabricados en oro y

74. El identificado con el n. ${ }^{\circ} 745$ se valoró en 4.500 libras; el n. ${ }^{\circ} 902$ en 5.000 libras; el n. ${ }^{\circ} 991$ también con 5.000 libras; el n. ${ }^{\circ} 925$ en 1.392 libras, y el último, el n. ${ }^{\circ}$ 1064, en la misma cantidad. AGP, Reinados, Carlos IV, Casa, leg. 185.

75. Ambos relojes responden a una de las tipologías más características de Breguet y más solicitada por su clientela, lo que demuestra que los monarcas siempre compraron las piezas más novedosas del mercado. AGP, Reinados, Carlos IV, Casa, leg. 189.

76. Aranda Huete, A. Relojes de reyes, pp. 149-150. 
adornados con piedras preciosas se consideraban como una joya y como tal se custodiaban junto con las joyas de los monarcas en el oficio de guardajoyas. Los adquirieron a los mejores relojeros del siglo, tanto de la escuela inglesa como de la francesa. Es de lamentar que las descripciones de las cajas esmaltadas sean tan escuetas y que no se registren los asuntos representados en ellas. Debieron reflejar los habituales de cada época y estilo artístico. Estos relojes desgraciadamente se han perdido con el paso del tiempo y no conservamos ejemplares en los museos nacionales.

\section{BiBLIOGRAFÍA}

Aranda Huete, Amelia. La joyería en la corte durante el reinado de Felipe V e Isabel de Farnesio. Madrid: Fundación Universitaria Española, 1999.

ARAnda Huete, Amelia. "Los relojes del reinado de Fernando VI y Bárbara de Braganza». Reales Sitios, 2009, n. ${ }^{\circ}$ 181, pp. 60-76.

ARANDA HuETe, Amelia. Relojes de Reyes en la corte española del siglo XVIII. Madrid: Patrimonio Nacional, 2011.

Berner, G.-A. Dictionnaire professionnel illustré de l'horlogerie I+II. Bienne: Federación de la Industria relojera suiza, 2002.

BREguet, Emmanuel. Breguet horloger depuis 1775. Vie et postérité d'Abraham-Louis Breguet (1747-1823). Paris: Alain de Gourcuff Éditeur, 1997.

CARDINAL, Catherine. La montre des origines au XIX siècle. Fribourg: Office du Livre, 1985.

CARDINAL, Catherine. Les montres et horloges de table du musée du Louvre. La collection Olivier. Paris: Réunion des Musées Nationaux, 2000.

CHAPIRO, Adolphe. La montre française du XVIe siècle jusqu'à 1900. Paris: Les éditions de l'Amateur, 1991.

Cummins, Genevieve. How the watch was worn. A fashion for 500 years. Suffolk: Antique Collectors' Club, 2010.

FERnÁNDEZ-Miranda y LOZANA, Fernando. Inventarios Reales, Carlos III, 1789-1790. Madrid: 1989.

JunQuera, Paulina. Relojería palatina. Antología de la colección real española. Madrid: Biblioteca Literaria del relojero, Ed. Roberto Carbonel Blasco, 1954.

Thompson, David. The History of watches. New York-London: Abbeville Press Publishers, 2008. 